\title{
Pigmentos y pinturas en Antofagasta de la Sierra. ANÁLISIS COMPOSICIONAL DE MINERALES COLORANTES Y SUPERFICIES cerámicas (provincia de Catamarca, Argentina)
}

\author{
Verónica Puente a \\ P. Mariela Desimone ${ }^{b}$ \\ José M. Porto López ${ }^{c}$
}

\begin{abstract}
Resumen
Se presentan los resultados obtenidos sobre el estudio composicional de pinturas y engobes aplicados sobre cerámica arqueológica de distintos estilos recuperada en Punta de la Peña, Peñas Coloradas y Paicuqui, localidades arqueológicas de la microrregión de Antofagasta de la Sierra (provincia de Catamarca, Argentina). Se evalúa la variabilidad de minerales empleados tanto en piezas de producción local como en recipientes de procedencia alóctona. Además, se detectó que en Paicuqui afloran depósitos de minerales colorantes de distintas tonalidades y se recuperaron también evidencias de procesamiento de pigmentos. A través de análisis por difracción de rayos $X$ y microespectroscopia Raman se caracteriza la composición de estas materias primas y se discute su posible uso en la cerámica estudiada. La información generada contribuye, por un lado, al conocimiento de las prácticas locales de producción, circulación y consumo de alfarería y de saberes para su elaboración que se desarrollaron en la región en el rango cronológico c. 1000-1500 d.C. y, además, conforma el principio de una base de datos necesaria para la referencia de fuentes de pigmentos, escasamente registrados en el Noroeste Argentino.
\end{abstract}

Palabras clave: pinturas, pigmentos, difracción de rayos X, microespectroscopia Raman, Noroeste Argentino

\section{Abstract}

PIGMENTS AND PAINTS IN ANTOFAGASTA DE LA SIERRA. COMPOSITIONAL ANALYSIS OF MINERALS AND CERAMIC SURFACES (PROVINCE OF CATAMARCA, ARGENTINA)

The results of compositional studies of paints and slips applied on archaeological ceramics of different styles recovered at Punta de la Peña, Peñas Coloradas and Paicuqui, archaeological sites of Antofagasta de la Sierra microrregion (Catamarca Province, Argentina), are presented and discussed. The variability of minerals used in local, as well as, in foreign pieces is evaluated. Furthermore, pigment deposits of diverse colors and also evidences of pigment processing were found. These materials were characterized by X-ray diffraction and Raman microspectroscopy and their possible appli-

\footnotetext{
a Consejo Nacional de Investigaciones Científicas y Técnicas (CONICET). Laboratorio de Arqueología, Universidad Nacional de Mar del Plata (LARBO-UNMdP)

Correo electrónico: vpuente78@yahoo.com.ar

${ }^{b}$ Instituto de Investigaciones en Ciencia y Tecnología de Materiales (INTEMA, CONICET - UNMdP)

Correo electrónico: mdesimone@fi.mdp.edu.ar

c Laboratorio de Arqueología, Universidad Nacional de Mar del Plata (LARBO-UNMdP)

Correo electrónico: jmplopez@fi.mdp.edu.ar
} 
cation in the fabrication of the studied ceramics is discussed. This information may contribute to the knowledge of the local pottery production, circulation ways and use, and of the elaboration techniques developed in this region during the chronological range ca. 1000-1500 AD. Also, may serve as the start of an empirical reference database of raw materials sources, which are scarcely registered in Argentine Northwest.

Keywords: paints, pigments, X-Ray diffraction, Raman microspectroscopy, Northwestern Argentina

\section{Introducción}

La microrregión de Antofagasta de la Sierra (en adelante ANS) es una cuenca endorreica de altura, ubicada entre los 3600 y $4900 \mathrm{msnm}$, en el departamento homónimo, provincia de Catamarca, Argentina (Aschero 1988). En la primera mitad del segundo milenio de la era (c. 1000-1500 d.C.) los sectores intermedios de las quebradas subsidiarias al río Punilla, recurso hídrico principal de la región, fueron habitados por grupos humanos cuya subsistencia se basó principalmente en el pastoreo de camélidos y agricultura a pequeña escala. Asimismo, a través de diversas modalidades de interacción a distancias amplias, estos grupos accedieron a recursos lejanos y de pisos ecológicos diferenciados, entre ellos, los valles orientales y meridionales del Noroeste Argentino (NOA). Esta forma de vida que integró elementos puneños y vallistos se muestra a nivel arqueológico en la coexistencia de bienes y materias primas locales y alóctonas, entre ellos, cerámicas, obsidianas, turquesas, semillas de algarrobo, espinas de cardón, etc. (Cohen 2014; López Campeny et al. 2014; Martel 2014; Escola et al. 2016; Martel et al. 2017; Puente, Plá e Invernizzi 2017; entre otros). La interacción interregional también involucró la circulación de saberes evidenciada, por ejemplo, en la producción local de recipientes cerámicos que combinaron recursos plásticos y técnicos característicos de vasijas de otras regiones, logrando un producto propio que sintetiza elecciones estilísticas diversas (Puente, Plá e Invernizzi 2017).

Con el propósito de contribuir al estudio de las prácticas locales de producción, circulación y consumo de alfarería y de saberes para su elaboración, en este trabajo se presentan los análisis realizados sobre el estudio de pinturas y engobes aplicados en cerámicas recuperadas en sitios de las localidades arqueológicas de Punta de la Peña, Peñas Coloradas y Paicuqui. Las dos primeras se ubican en la quebrada del río Las Pitas, en tanto la última se encuentra aproximadamente a 13 kilómetros de distancia, en la confluencia de los ríos Curuto y Punilla (Fig. 1). Además, en Paicuqui afloran depósitos de pigmentos minerales que varían entre tonos ocres, blancos, grises y negros, y también se recuperaron evidencias de su procesamiento, concretamente la mano de un mortero y un "pan de pigmentos amasado». Estos hallazgos fueron encontrados en el sector de estructuras residenciales del sitio Paicuqui 1 o «Peña del Medio» (como la denominan los lugareños), y brindan la posibilidad de analizar distintos pasos dentro de la secuencia de producción de pinturas arqueológicas y evaluar su potencial uso en la cerámica.

Los objetivos de este trabajo son:

1. Caracterizar la composición de los pigmentos minerales que afloran en la región.

2. Analizar los residuos conservados en la mano del mortero para determinar si fue empleada en la molienda de los pigmentos que afloran en la zona.

3. Determinar la composición del «pan de pigmentos» arqueológico.

4. Identificar la composición mineral de las pinturas y engobes aplicados sobre la cerámica.

El abordaje de estos objetivos permitirá discutir si hay diferencias o no entre los pigmentos usados en la alfarería hallada en los sitios de ambas quebradas y evaluar si se utilizaron las materias primas colorantes locales. Las técnicas analíticas implementadas son difracción de Rayos X y microespectroscopía Raman. 


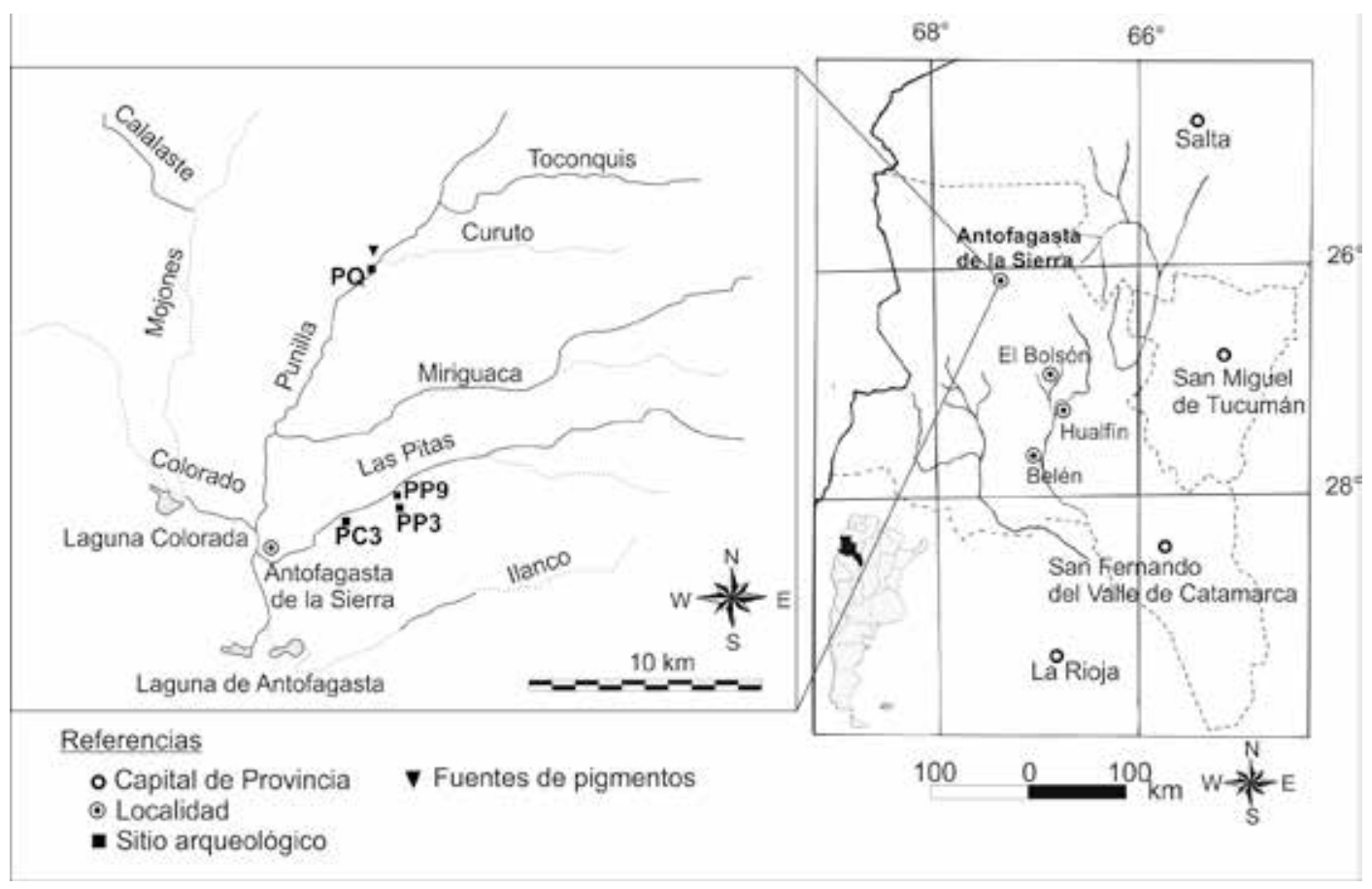

Figura 1. Ubicación geográfica de la región, los sitios y las fuentes de pigmentos. (V. Puente).

\section{Las muestras analizadas y su procedencia}

\subsection{Características generales de los sitios}

Las localidades arqueológicas Peñas Coloradas y Punta de la Peña se ubican en el curso inferior y medio del río las Pitas y están a 3 kilómetros de distancia entre sí. La primera de ellas está conformada por cuatro depósitos tabulares de ignimbrita que fueron ocupados en su base y también en la cumbre de la peña 3 (PC3c). En esta última, se construyeron la mayor cantidad de estructuras $(\mathrm{N}: 24)$, entre las que se destacan las asociadas a actividades residenciales y depósitos vinculados a rituales de muerte, fechadas entre los años 810-1620 d.C. El acceso al sitio se encontraba restringido a un sector del perímetro, el cual estuvo originalmente rodeado por una muralla. La elección del emplazamiento y la diagramación del espacio construido respondieron a estrategias de defensa, ocultamiento, control visual y culto a los ancestros. Además, en la base del farallón se registraron restos de antiguos canales de regadío para solventar una producción agrícola a pequeña escala (Cohen 2014). Las cerámicas analizadas se recuperaron en la cima de esa peña (PC3c), en la base de la peña 2 (PC2) y en el sector cercano a la vega (PCv).

De la localidad de Punta de la Peña se analizó material procedente de dos sitios: Punta de la Peña 3 sector C (PP3-C) y Punta de la Peńa 9 sector III (PP9-III). El primero se emplaza sobre la ladera de otro depósito tabular de ignimbrita y se caracteriza por una sucesión discontinua de estructuras residenciales y productivas — corrales y patios-, construidas aprovechando los bloques grandes desprendidos de la peña. El sitio posee una secuencia de ocupación amplia que fue datada entre c. 1500 y 300 AP (Quiroga 2014). A pocos metros, sobre una terraza alta y más cerca del cauce del río está PP9-III, un sitio multicomponente que se utilizó como lugar de residencia, productivo y enterratorio. Sus ocupaciones se dataron entre c. 2000 y 500 años AP (Cohen 2005; Somonte y Cohen 2006). De estos dos últimos sitios, la cerámica analizada corresponde a momentos prehispánicos Tardíos (c. 1000-1500 d.C.). 
A 13 kilómetros en línea recta, sobre el sector de confluencia de los ríos Curuto y Punilla se encuentra la localidad de Paicuqui. La cerámica analizada procede de la base de dos farallones de ignimbrita, denominados PQ1 y PQ2. Específicamente, algunas muestras de PQ1 están asociadas a prácticas rituales que creemos involucraron el arrojo intencional de recipientes o fragmentos de ellos, desde la cumbre de la peña, aspecto que está siendo investigado. El resto de la cerámica, la mano del mortero y la masa de pigmentos están relacionados a recintos construidos en la base de la peña. Estudios constructivos y sobre la modalidad arquitectónica de la cima relacionan al sitio con los conceptos aimaras de Taypi y Tinku — centralidad y encuentro- y con observaciones astronómicas (Cohen y Ponce 2016; Ponce y Cohen 2018). Hasta el momento no se dispone de fechados absolutos, pero a partir de la variabilidad estilística y tecnológica de la cerámica y de las modalidades constructivas, se estima que el sitio fue ocupado en un rango temporal que abarca los períodos Tardío, Inka y Colonial Temprano.

En los sitios mencionados se recuperaron diversidad de objetos y recursos foráneos —obsidiana, maíz, semillas de algarrobo, cerámica, etc.-, que evidencian que la vida agrícola-pastoril estuvo articulada con modalidades de interacción a distancia con pisos ecológicos variados (Cohen 2005, 2014; Somonte y Cohen 2006; Quiroga 2014; Puente, Plá e Invernizzi 2017).

\subsection{Muestras cerámicas}

Se analizaron 14 fragmentos cerámicos correspondientes a piezas diferentes. Algunas de ellas fueron cubiertas por una espesa capa de engobe de color rojo y/o negro, sobre otras se plasmaron diseños iconográficos de color negro sobre un fondo de pintura roja, y en otras la pintura negra fue aplicada directamente sobre la tonalidad original de la pasta. Ocho tiestos proceden de la localidad de Peńas Coloradas, sitios PC2, PC3c y sector de la vega adyacente (PCv); dos de PP3-C, uno de PP9-III, dos de PQ1 y uno de PQ2.

La selección de estas muestras representa la variabilidad de vasijas pintadas recuperadas hasta el momento en los sitios mencionados. Por sus características se distinguen cinco grupos estilísticos: estilo Belén, estilo Molinos, negro sobre rojo, negro sobre naranja y engobe pulido (Tabla 1, Fig. 2). En algunos casos fue posible reconstruir de forma parcial o total el perfil de los recipientes (Puente, Plá e Invernizzi 2017). Análisis composicionales disponibles para algunos fragmentos permitieron diferenciar entre muestras de origen local y otras de procedencia alóctona. Las cerámicas reconocidas como de manufactura local poseen pastas que combinan inclusiones no plásticas compuestas principalmente por litoclastos volcánicos y cristaloclastos de cuarzo y feldespatos, componentes predominantes en las arenas de la región. Asimismo, análisis por activación neutrónica instrumental realizados sobre algunas muestras indican asociación química con una de las fuentes de arcilla cercana a los sitios. Estas piezas de origen local, también se diferencian entre sí por las características de sus pastas — densidad, tamaño del temperante, porosidad, matriz— resultado de modos de hacer diversos (Puente 2016; Puente, Plá e Invernizzi 2017).

Específicamente, los fragmentos Belén fueron hallados en la localidad de Peñas Coloradas y formaron parte de un puco y dos urnas, dos de ellos elaborados con materias primas de la zona. Las muestras de estilo Molinos proceden de los sitios de Punta de la Peńa, consisten en un fragmento de cuerpo y cuello de piezas cuya forma no podemos reconstruir y son de origen local. La cerámica pintada en color negro sobre rojo corresponde a fragmentos de piezas hallados en ambas localidades arqueológicas de la quebrada de Las Pitas y que fueron manufacturadas con materias primas locales. También de origen local es la muestra atípica pintada en negro sobre naranja — color natural de la pasta- recuperada en PC3c.

A diferencia de las Pitas, en Paicuqui, las piezas pintadas son muy pocas. Se incluyen en el análisis tres fragmentos de vasijas sobre las cuales se aplicó una espesa capa de engobe. Dos corresponden a bordes evertidos de recipientes con cuello y uno al borde de un puco o cuenco. Los datos petrográficos obtenidos recientemente para dos de las muestras indican que fueron manufacturadas 
Tabla 1. Las muestras cerámicas analizadas: variabilidad estilística y procedencia.

\begin{tabular}{llll}
\hline Muestra & Sitio & Estilo & Procedencia \\
\hline PC3c 3-9 & PC3c & Belén & Local \\
PCv 2-5 & PCv & Belén & Local \\
PC2 10-15 & PC2 & Belén & No local \\
36v & PC3c & Negro sobre Rojo & Local \\
51v & PC3c & Negro sobre Rojo & Local \\
sup2 & PC3c & Negro sobre Rojo & Local \\
47v & PC3c & Negro sobre Rojo & Local \\
PP3 7-2 & PP3C & Negro sobre Rojo & Local \\
PP3 6-1 & PP3C & Molinos & Local \\
PP9-466 & PP9-III & Molinos & Local \\
55v & PC3c & Negro sobre Naranja & Local \\
PQ 66A & PQ1 & Engobe pulido & No local \\
PQ33 & PQ2 & Engobe pulido & No determinado \\
PQ 66B & PQ1 & Engobe pulido & No local \\
\hline
\end{tabular}

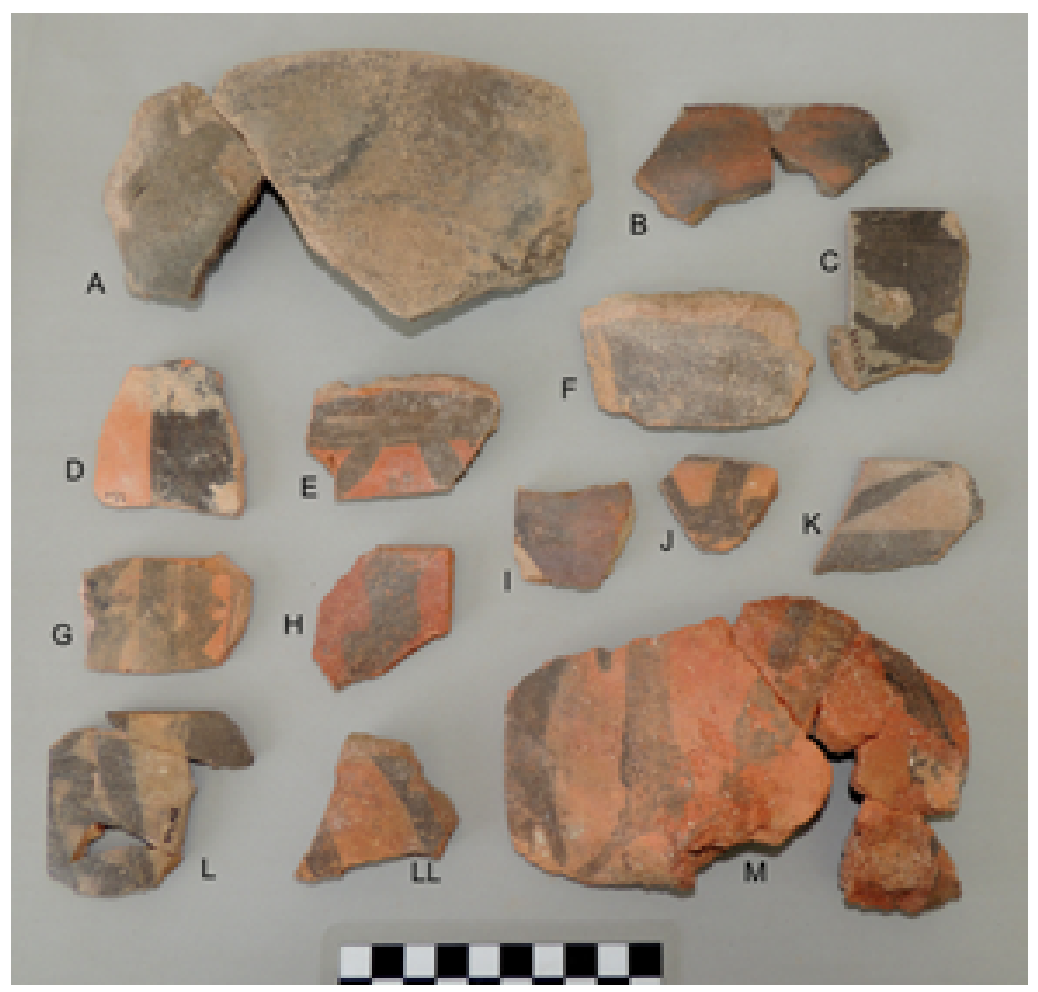

Figura 2. Fragmentos cerámicos analizados. Referencias: A (PQ66A), B (PQ33), C (PQ66B), D (55v), E (PC3c 3-9), F (51v), G (PP3 6-1), H (PCv 2-5), I (PC2 10-15), J (47v), K (36v), L (PP9-466), LL (sup 2), M (PP3 7-2). (V. Puente). 
con temperante de origen granítico. Este tipo de rocas no afloran en la zona y tampoco son un constituyente significativo de las arenas que transportan los ríos Curuto, Punilla y Las Pitas, por ello consideramos que su procedencia es alóctona (Puente et al. 2018).

De este modo, los casos estudiados no solo corresponden a sitios de dos quebradas diferentes, sino también representan variabilidad estilística, tecnológica y composicional. La heterogeneidad del conjunto analizado posibilita evaluar si los componentes minerales de las pinturas y engobes varían con relación a la diversidad mencionada.

\subsection{Pigmento arqueológico y herramienta para su procesamiento}

En Paicuqui se recuperó en la excavación del interior de un recinto ubicado en la base de PQ1, un «pan de pigmentos» de color rojo de 3.5 centímetros de largo que conserva marcas de su formatización (Fig. 3A). Además, se halló en superficie la mano de un mortero de piedra de 5.7 centímetros de alto y forma de gota, con restos de sustancias colorantes adheridas (Fig. 3B).

\subsection{Las fuentes de pigmentos}

Las fuentes de pigmentos minerales se encuentran en la localidad de Paicuqui y corresponden geológicamente a la formación Falda Ciénaga. Se trata de arcillas y pelitas con bajo a muy bajo grado de metamorfismo (Hongn y Seggiano 2001). Hay depósitos monocromos y otros donde colores distintos coexisten en la misma fuente (Fig. 4). Los tonos reconocidos varían entre la gama de ocres, blancos y grisáceos. Asimismo, se identificaron cristales cúbicos de color negro con leve magnetismo (Fig. 5). Estos crecen entre las láminas de arcillas y pelitas. Todos los afloramientos de pigmentos se encuentran en la base y alrededores de la «Peña del Medio» o PQ1 (Fig. 4).

Se analizaron un total de 12 muestras. Se utilizó la tabla Munsell para registrar la variabilidad cromática (Tabla 2).

\section{Técnicas analíticas y condiciones de los análisis}

Se aplicaron de manera complementaria análisis por microespectroscopía Raman y por difracción de rayos X. Dadas las diferencias entre ambas técnicas con relación al tamaño del área superficial analizada, a la profundidad de penetración del láser y de los rayos $\mathrm{X}$, y a las bases de datos disponibles, destacamos el beneficio de aplicar de forma combinada ambas técnicas analíticas (Puente et al. 2017). Los análisis fueron realizados en el Instituto de Investigaciones en Ciencia y Tecnología de Materiales (INTEMA, CONICET - UNMdP).

\subsection{Microespectroscopía Raman (micro-Raman)}

Se utilizó un instrumento Renishaw inVia Reflex equipado con un láser de diodo de $\lambda=785 \mathrm{~nm}$ en combinación con una rejilla de 1,200 rendijas $/ \mathrm{mm}$. El software utilizado fue Wire 3.4. Se trabajó con un objetivo Leica de magnificación 50x (NA: 0.75). Las condiciones de medida fueron seleccionadas para no dańar o alterar la composición de la muestra: tiempo de exposición de 1 segundo con 5 acumulaciones y $0.5 \%$ de potencia del láser. Dado el tamaño pequeño del spot del láser que incide sobre la superficie de las muestras en las condiciones de medida realizadas $(1.5-2 \mu \mathrm{m}$ de diámetro) se realizaron al menos cinco análisis para cada muestra y se complementaron los resultados para obtener una «representación estadística» de las mismas. 
Figura 3. A- Pigmento amasado. B-Mano de mortero. (V. Puente).
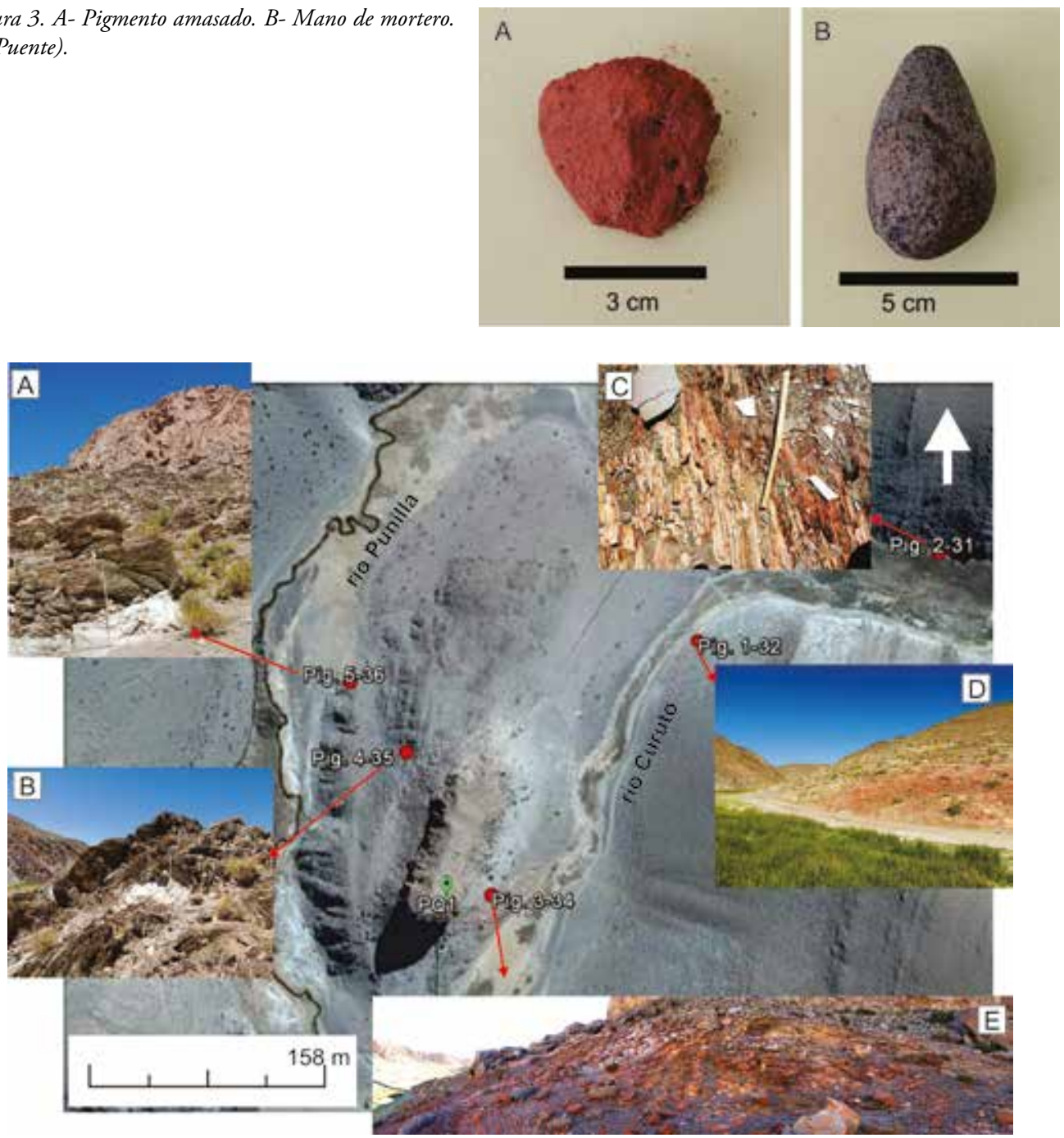

Figura 4. Imagen satelital (Google Earth, fecha 5/16/2016) con la ubicación de los afloramientos de pigmentos. A y B- depósitos de colores blanco y grises; $C$-detalle de tonos ocres intercalados; $D$ y E-depósitos de tonos ocres intercalados. Referencias: Pig. (Pigmento). (V. Puente).

Figura 5. Cristales cúbicos de color negro. (V. Puente).

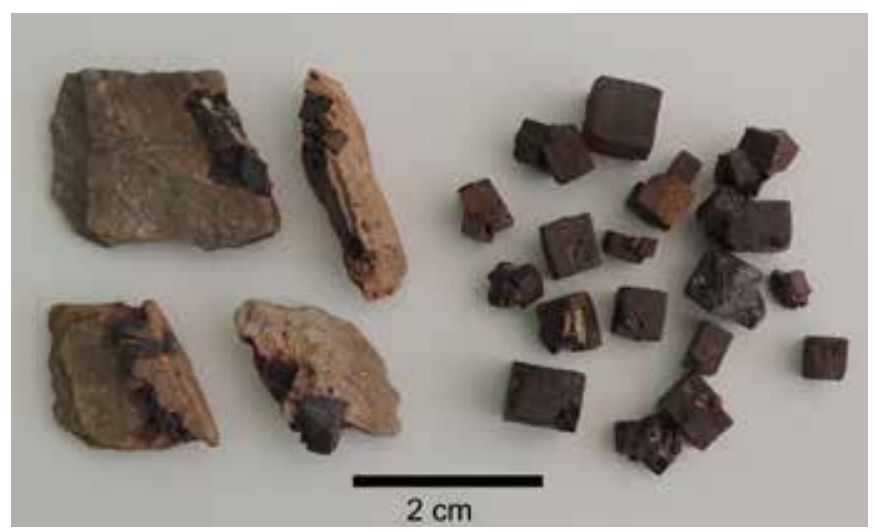


Tabla 2. Pigmentos minerales de Paicuqui: color y composición. Referencias: $G$ (goethita), Q (cuarzo), $H$ (hematita), Mi (mica), K (kaolinita), An (anatasa), Cl (clorita), Mu (muscovita), Ru (rutilo), Ar (aragonita).

\begin{tabular}{llll}
\hline Muestra & Color y código Munsell & DRX & Micro-Raman \\
\hline 2-33 cristal cúbico & Gris rojizo oscuro 10R 3/1 & G, Q, H & G, H \\
3-34a & Rojo débil 10R 4/4 & Q, Mi, K, H & Q, Mu, K?, H \\
2-31a & Rojo claro 2.5YR 6/6 & Q, Mi, K, H & Q, H \\
1-32a & Rojo 2.5 YR 5/6 & Sin analizar & Q, Mu, H \\
1-32b & Gris claro 2.5Y 7/1 & Q, Mi y posible K & Q, K, H \\
2-31b & Gris claro 10 YR 7/2 & Q, Mi, An, Cl & Q, An, Cl, H \\
4-35. & Gris claro 2.5Y 7/1 & Q, Mi, An, K & Q, K, Cl, H \\
4-36. & Gris claro 2.5Y 7/1 & Q, Mi, K, An & Q, Mu, K, Cl \\
2-31d & Gris rosado 7.5YR 7/2 & Sin analizar & Q, An, Ru \\
2-31c & Blanco 10YR 8/1 & Q, Mi, K & Q, K, Ru, Ar, H \\
3-34b & Blanco 2.5 Y 8/1 & Q, Mi, K & Q, Mu, K, Ru, Ar \\
3-34c & Blanco rosáceo 7.5YR 8/2 & Sin analizar & Q, Ru, H \\
\hline
\end{tabular}

\subsection{Difracción de rayos $\mathrm{X}(\mathrm{DRX})$}

El análisis se llevó a cabo con un difractómetro PANalytical X-Pert Pro a $40 \mathrm{kV}$ - $40 \mathrm{~mA}$, usando radiación $\mathrm{CuK \alpha}\left(1.5418 \AA\right.$ ) y monocromador de grafito, sobre el rango angular $5-70^{\circ} 2 \theta$ con un intervalo angular $0.02^{\circ}$ y $0.5 \mathrm{~s}$ de tiempo de lectura.

Los minerales colorantes muestreados en la región fueron molidos manualmente en mortero de ágata a pasar tamiz USS $325(53 \mu \mathrm{m})$ y analizados en polvo. En el caso de las muestras cerámicas, con el fin de respetar su integridad, fueron analizadas sin moler, seleccionando zonas planas de las superficies decoradas. Aun así, la alineación de las piezas en el portamuestras no siempre fue perfecta debido a la inevitable existencia de pequeñas irregularidades superficiales. Para corregir las eventuales desviaciones angulares resultantes se tomó como referencia la posición angular del pico (101) del cuarzo, presente en todas las muestras.

Cabe aclarar que, debido al tamaño y forma de algunas muestras arqueológicas, el análisis por DRX no pudo aplicarse en todos los casos.

\section{Resultados}

\subsection{Caracterización composicional de los pigmentos minerales que afloran en Paicuqui}

En los colores blancos y grises, los análisis por DRX permitieron reconocer en todas las muestras la presencia de cuarzo y mica (denominación genérica utilizada en este trabajo para las arcillas del grupo de las micas - illita, muscovita, etc. - que no son diferenciables en los difractogramas). Además, se identificó kaolinita, anatasa y clorita, en algunos casos juntos en el mismo depósito y en otros, distribuidos de manera diferencial (Tabla 2, Fig. 6). El análisis por micro-Raman logró 


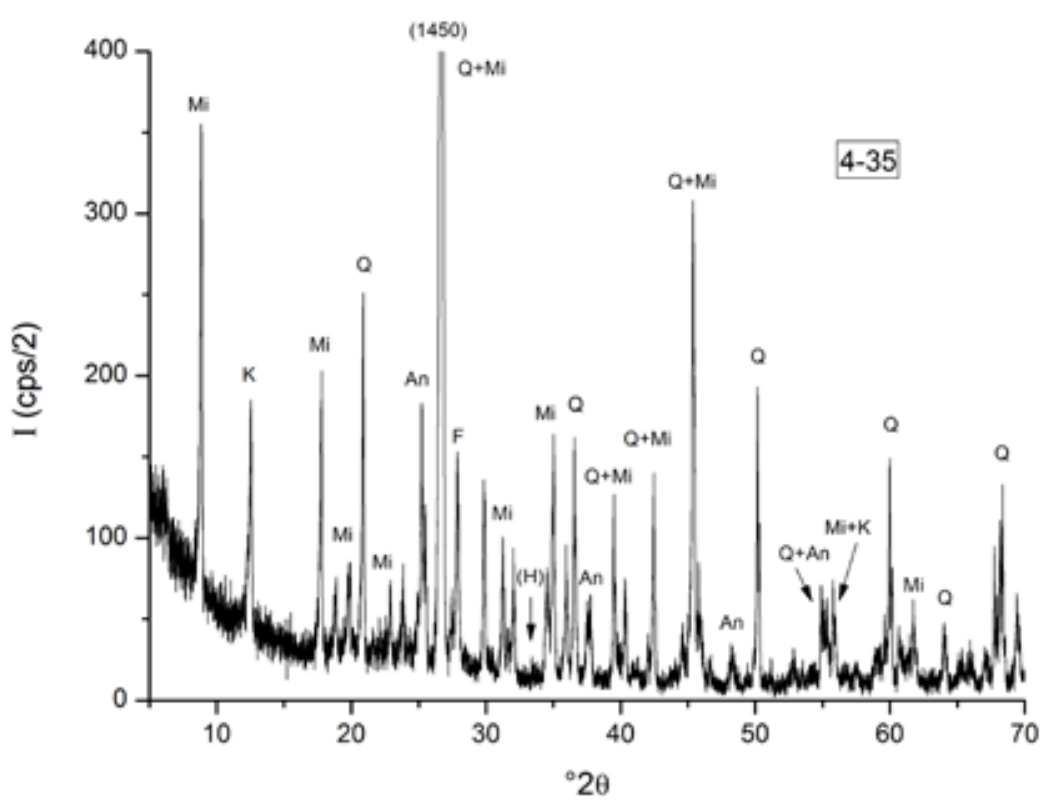

Figura 6. Difractograma de la muestra 4-35, color gris claro. Referencias: Q (cuarzo), $H$ (hematita), $K$ (kaolinita), Mi (micas), An (anatasa) (J. M. Porto López).

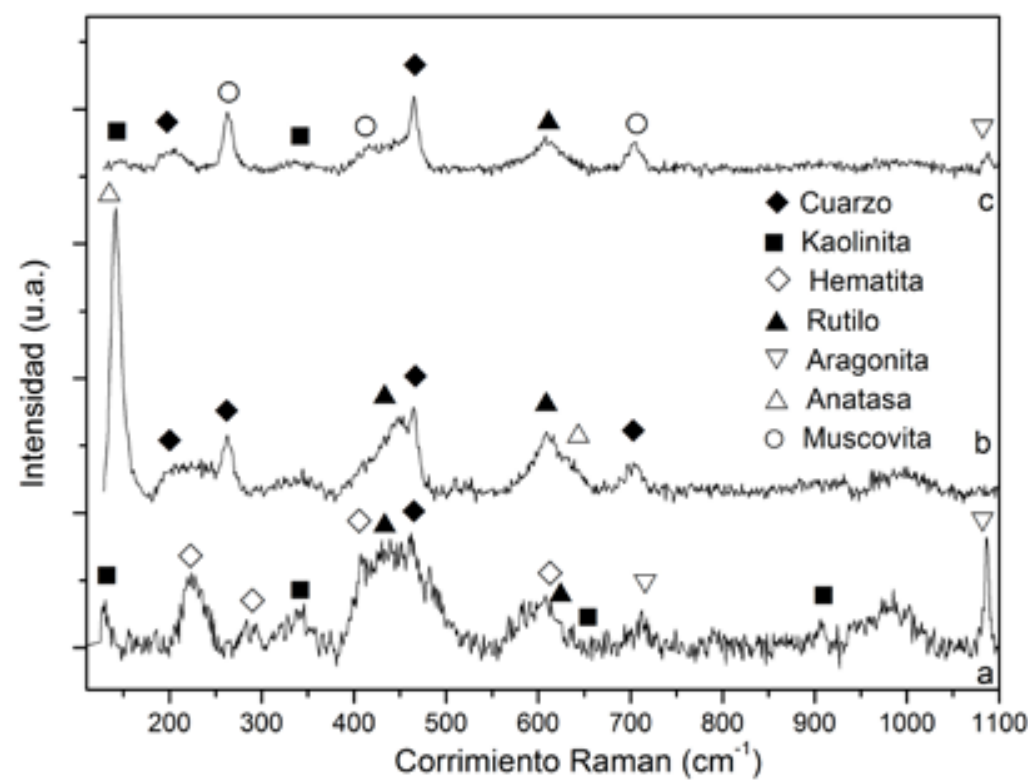

Figura 7. Espectro Raman de muestras: a) 2-31c color blanco, b) 2-31d color gris rosado y c) 3-34b de color blanco (P. M. Desimone). 


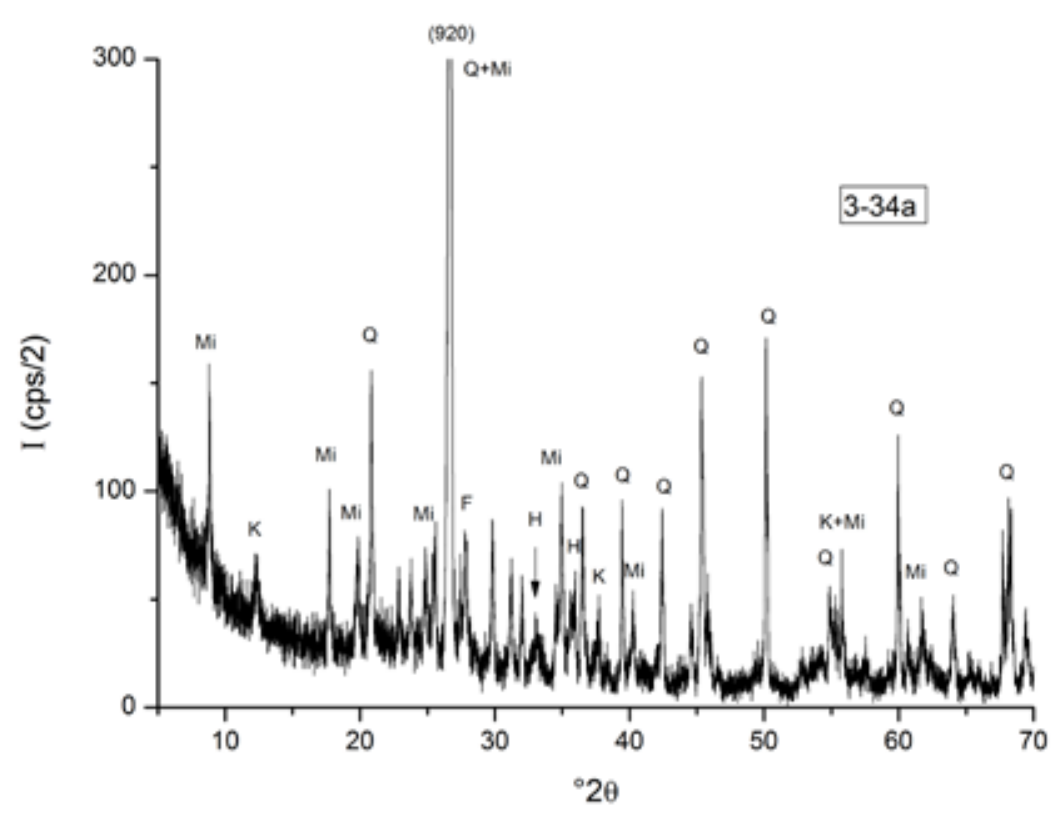

Figura 8. Difractograma correspondiente a la muestra 3-34a, color rojo débil. Referencias: $Q$ (cuarzo), $H$ (hematita), Mi (micas), K(kaolinita) (J. M. Porto López).

resultados coincidentes con los recién mencionados (Fig. 7). En todas las muestras se evidencia la presencia de cuarzo por sus picos característicos a 263, 463 y $699 \mathrm{~cm}^{-1}$ (Akyuz et al. 2008). La mayoría de ellas presentan kaolinita y hematita, evidenciadas por los picos a 130, 340, 636 y $915 \mathrm{~cm}^{-1}$ de la kaolinita y a 222, 295, 410, y $610 \mathrm{~cm}^{-1}$ de la hematita (Kloprogge 2017). Además, en algunas muestras se detectó aragonita por su pico característico a $1085 \mathrm{~cm}^{-1}$, rutilo por sus picos más intensos en 447 y $611 \mathrm{~cm}^{-1}$ (Murad 1997) y muscovita por los picos a 262, 408 y $703 \mathrm{~cm}^{-1}$.

Respecto a los tonos rojos, ambas técnicas analíticas determinaron la presencia de hematita como responsable del color. Además, se reconocen cuarzo, mica y kaolinita como elementos secundarios (Figs. 8 y 9 a).

Por último, los cristales cúbicos de color negro -según tabla Munsell gris rojizo oscuro-, fueron analizados en su estado original y también molidos en mortero de ágata. Al molerlos, el color negro desapareció y se obtuvo una tonalidad naranja-amarillenta. A través de ambas técnicas se determinó que se trata de cristales de goethita $(\alpha-\mathrm{FeOOH})$, con pequeñas cantidades de hematita y cuarzo en superficie (Figs. 9b y 10). La goethita por micro-Raman se identifica principalmente con los picos a 242, 296, 392, 479 y $550 \mathrm{~cm}^{-1}$. En DRX, los picos más intensos de la hematita (a $33.2^{\circ} 2 \theta$ y $\left.35.6^{\circ} 2 \theta\right)$ están superpuestos con picos de goethita (a $33.2^{\circ} 2 \theta$ y $\left.35.5^{\circ} 2 \theta\right)$, pero en el difractograma se pudo detectar la presencia de hematita por el pico débil (20\%) a $24^{\circ} 2 \theta$.

\subsection{Caracterización composicional de la mano de mortero y del pan de pigmentos}

Por sus características morfológicas y la conservación de microrrestos de sustancias colorantes, la mano de mortero solo fue analizada por micro-Raman. Al respecto se identificó la presencia de hematita, anatasa, cuarzo, muscovita, yeso y la posible presencia de magnetita. El yeso se reconoce por su pico agudo característico que se encuentra a $1,009 \mathrm{~cm}^{-1}$, en tanto la banda de la magnetita se evidencia a $670 \mathrm{~cm}^{-1}$ en el espectro Raman (Fig. 11, Tabla 3). 
Figura 9. Espectro Raman de: a) muestra 3-34a de color rojo débil, b) 2-33 (cristal cúbico) color gris rojizo oscuro (P. M. Desimone).

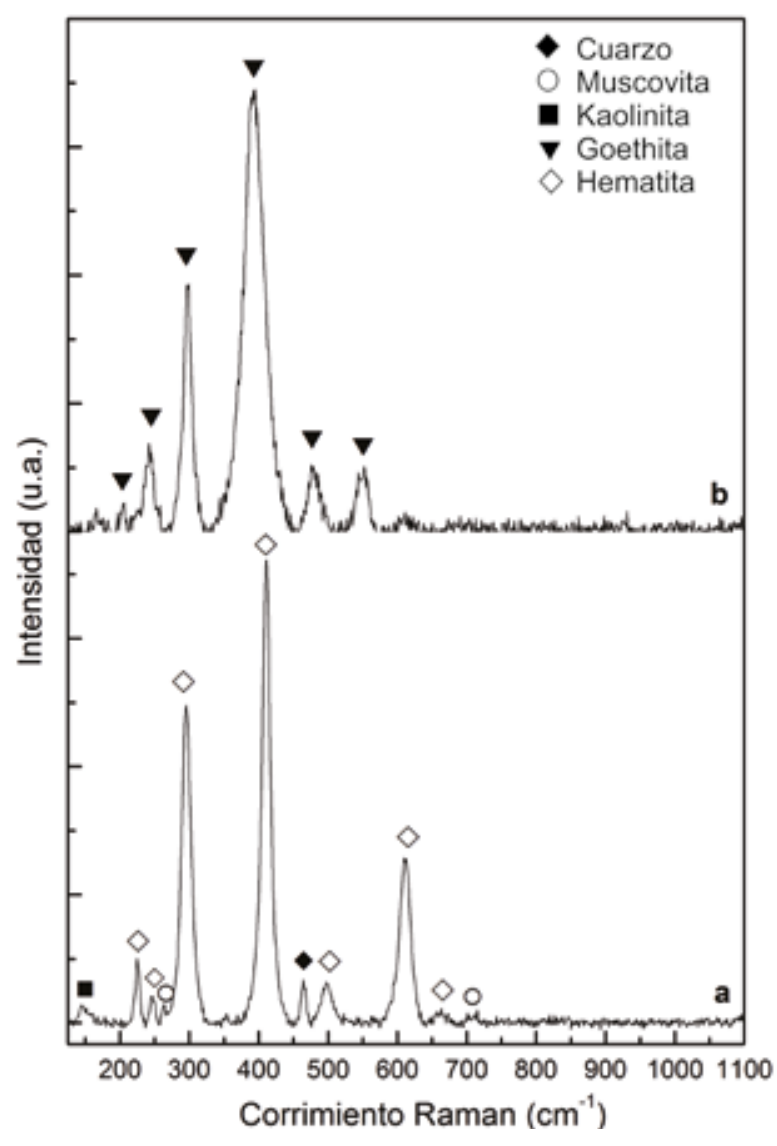

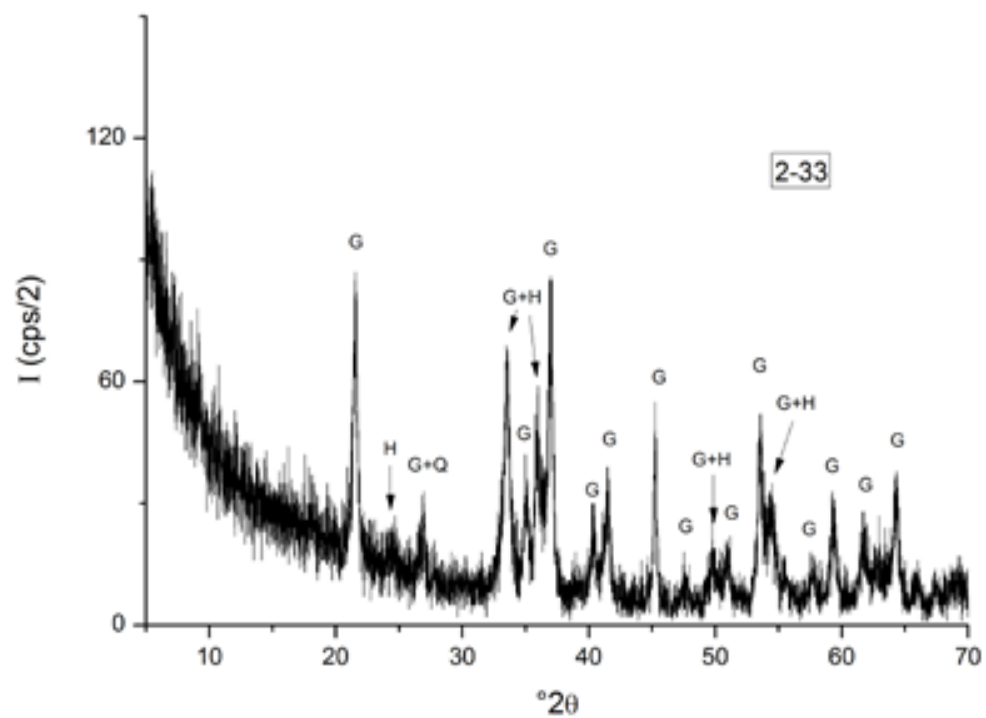

Figura 10. Difractograma de los cristales cúbicos, muestra 2-33. Referencias: Q (cuarzo), $H$ (hematita), G (goethita) (J. M. Porto López). 


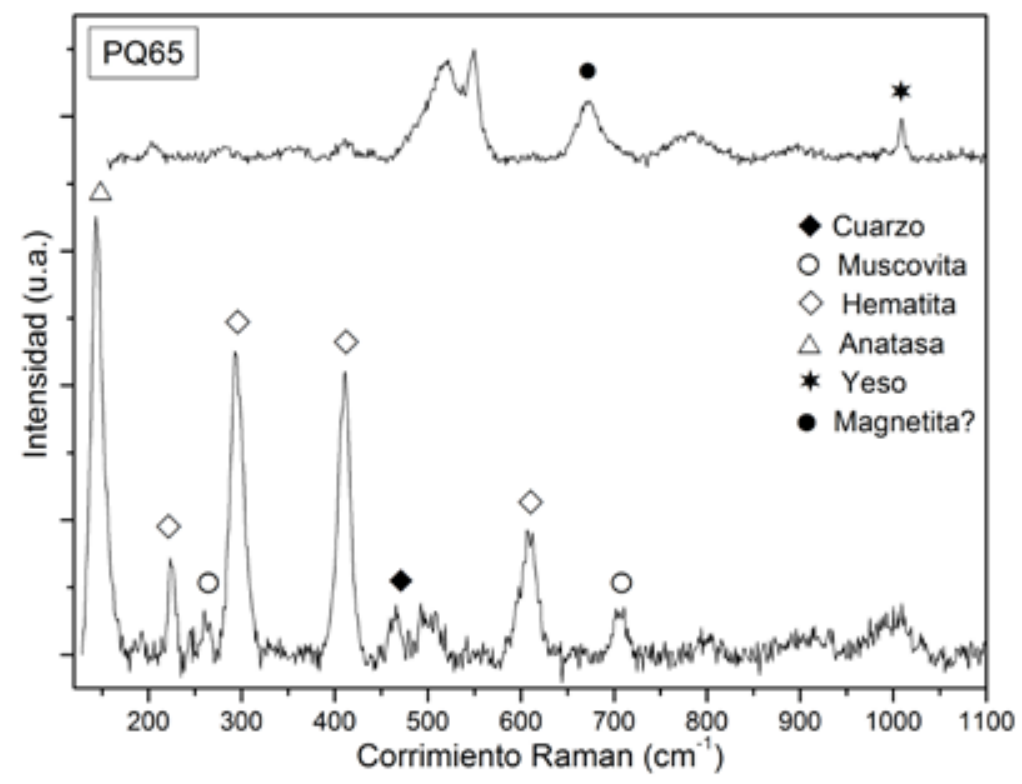

Figura 11. Espectro Raman correspondiente a la mano de mortero. Se exponen los espectros correspondientes a dos medidas de la misma muestra (P. M. Desimone).

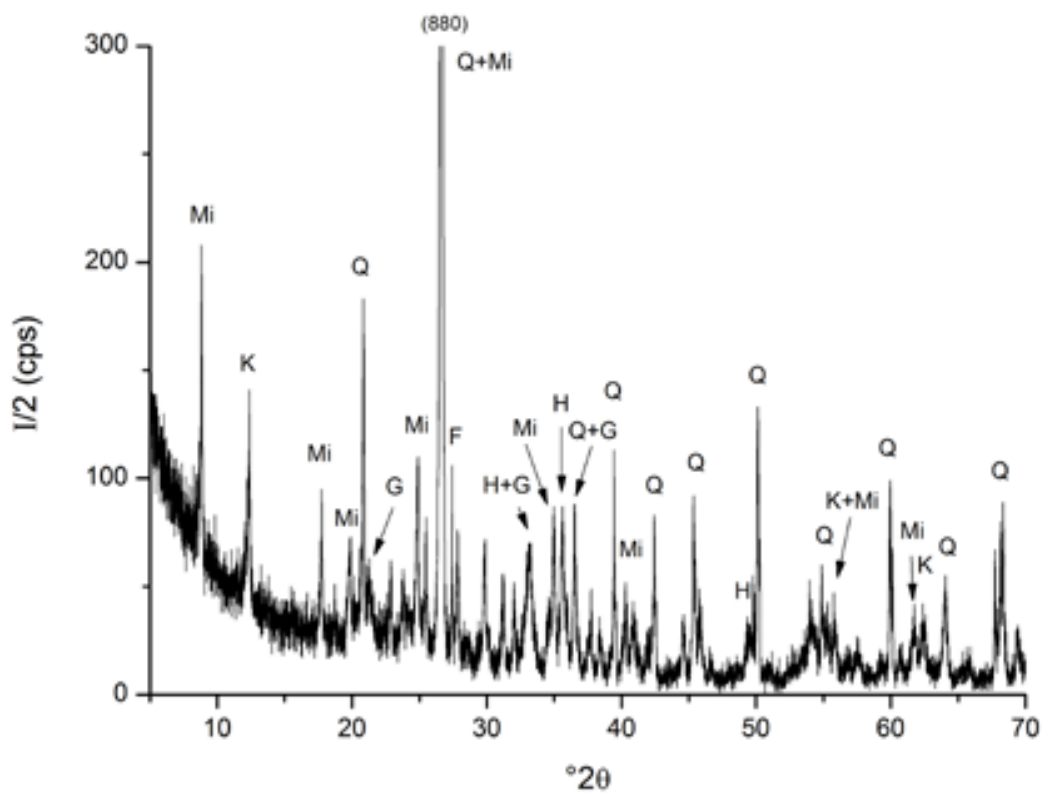

Figura 12. Difractograma correspondiente al pan de pigmentos. Referencias: $Q$ (cuarzo), Mi (micas), $H$ (hematita), $K$ (kaolinita), G (goethita) (J. M. Porto López). 


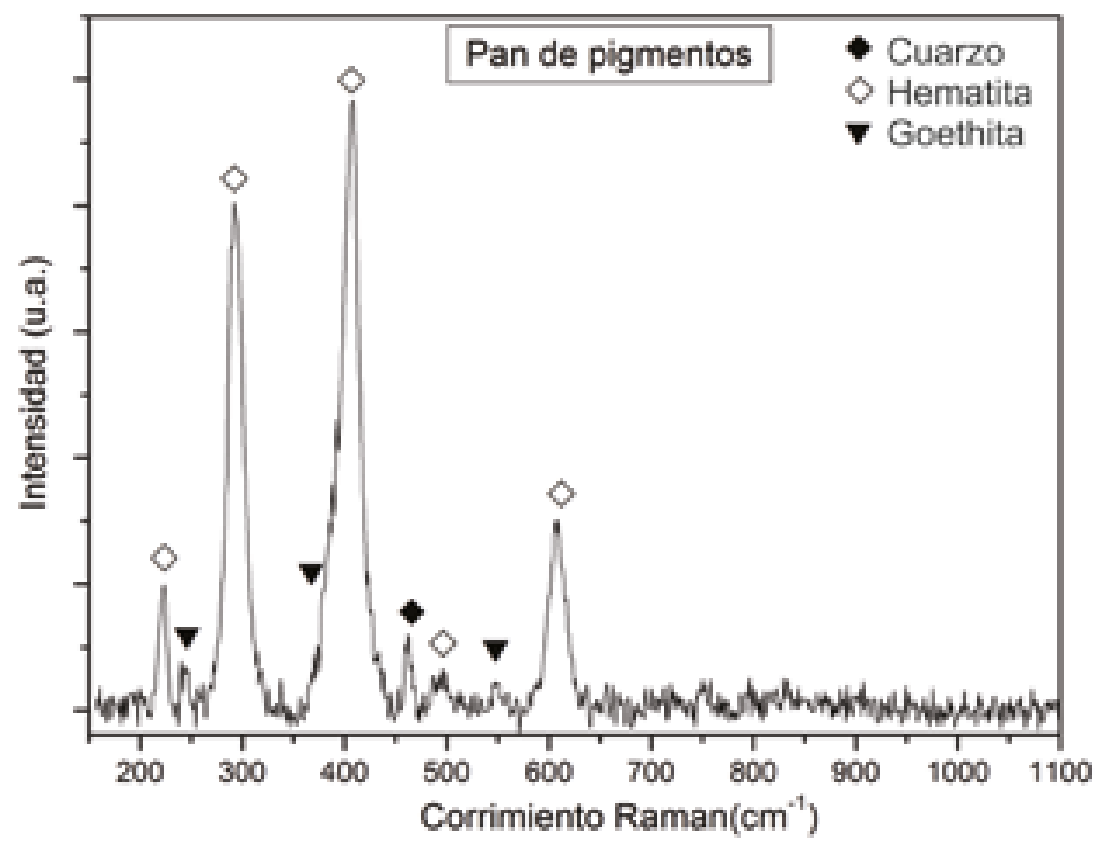

Figura 13. Espectro Raman correspondiente al pan de pigmentos (P. M. Desimone).

Tabla 3. Resultados composicionales del pan de pigmentos y mano del mortero. Referencias: $Q$ (cuarzo), $M i$ (micas), $H$ (hematita), K(kaolinita), G (goethita), $Y$ (yeso), An (anatasa), M (magnetita), Mu (muscovita).

\begin{tabular}{llll}
\hline Muestra & Color y código Munsell & DRX & Micro-Raman \\
\hline Pan de pigmentos & Rojo 2.5YR 4/8 & Q, Mi, H, K, G & Q, H, G \\
PQ65 (mano de mortero) & - & Sin analizar & H, An, Q, Mu, Y, M? \\
\hline
\end{tabular}

La pequeña masa de pigmento rojo se analizó mediante ambas técnicas analíticas. Por DRX se reconoció la presencia de hematita, goethita, cuarzo, kaolinita y micas (Fig. 12, Tabla 3). En tanto por micro-Raman se identificó hematita, goethita y cuarzo (Fig. 13).

\subsection{Caracterización composicional de pinturas y engobes en cerámica}

La pintura y el engobe rojo aplicados sobre las distintas muestras estudiadas, corresponden en todos los casos a hematita. En tanto, los cromóforos responsables de la pintura negra son una combinación de magnetita y/o titanomagnetita y óxidos de manganeso (Tabla 4). Estos últimos solo se detectaron por micro-Raman ya que no es posible hacerlo por DRX debido a que tanto la bixbyita $\left(\mathrm{Mn}_{2} \mathrm{O}_{3}\right)$ como la hausmannita $\left(\mathrm{Mn}_{3} \mathrm{O}_{4}\right)$ son poco cristalinos e isoestructurales con los óxidos de hierro correspondientes (hematita y magnetita); de este modo, dada la similitud en los radios iónicos de los cationes, sus difractogramas son prácticamente indistinguibles (Figs. 14, 15; Tabla 4). La banda más intensa correspondiente a los óxidos de manganeso en el espectro Raman se encuentra a $625-645 \mathrm{~cm}^{-1}$ y las correspondientes a magnetita y titanomagnetita a 670 y 690-700 $\mathrm{cm}^{-1}$, respectivamente. En algunos espectros no es posible diferenciar entre las bandas de estos dos últimos compuestos, por ello en la tabla indicamos su presencia como magnetita/titanomagnetita. 
Tabla 4. Resultados composicionales de las pinturas y engobes de color negro. Referencias: G (goethita), Q (cuarzo), $H$ (hematita), Mi (mica), K (kaolinita), An (anatasa), Cl (clorita), $M$ (magnetita), Ru (rutilo), Ar (aragonita), TM (titanomagnetita), $M u$ (muscovita), Mn (óxidos de manganeso), PO4 (fosfatos), Al (albita), F (feldespatos).

\begin{tabular}{|c|c|c|c|c|}
\hline Estilo & Muestra & Sitio & DRX & Micro-Raman \\
\hline \multirow{3}{*}{ Belén } & РC3c 3-9 & $\mathrm{PC} 3 \mathrm{c}$ & $\mathrm{H}, \mathrm{Q}, \mathrm{F}, \mathrm{Mi}$ & $\mathrm{Mn}, \mathrm{M}$ ?, $\mathrm{PO}_{4}, \mathrm{H}, \mathrm{Q}, \mathrm{Al}$ \\
\hline & PCv 2-5 & $\mathrm{PCv}$ & TM, H, Q, F & $\mathrm{Mn}, \mathrm{M} / \mathrm{TM}, \mathrm{PO}_{4} ?$ \\
\hline & PC2 10-15 & PC2 & Sin analizar & $\mathrm{Mn}, \mathrm{M} / \mathrm{TM}$ \\
\hline \multirow{5}{*}{ Negro sobre rojo } & $47 \mathrm{v}$ & PC3c & M?, TM, Q, F, Mi & $\mathrm{Mn}, \mathrm{M} / \mathrm{TM}$ \\
\hline & $51 \mathrm{v}$ & $\mathrm{PC} 3 \mathrm{c}$ & Sin analizar & Mn, M/TM, H, Q \\
\hline & $\sup 2$ & PC3c & $\mathrm{M}, \mathrm{Q}, \mathrm{F}, \mathrm{Mi}$ & $\mathrm{Mn}, \mathrm{M} / \mathrm{TM}, \mathrm{PO}_{4}$ ?, $\mathrm{R}, \mathrm{Al}$ \\
\hline & $36 v$ & PC3c & Sin analizar & $\mathrm{Mn}, \mathrm{M} / \mathrm{TM}, \mathrm{Q}, \mathrm{PO}_{4}$ ? \\
\hline & PP3 7-2 & $\mathrm{PP} 3 \mathrm{C}$ & $\mathrm{M}, \mathrm{H}, \mathrm{Q}, \mathrm{F}$ & $\mathrm{Mn}, \mathrm{M} / \mathrm{TM}, \mathrm{Q}$ \\
\hline \multirow{2}{*}{ Molinos } & PP3 6-1 & $\mathrm{PP} 3 \mathrm{C}$ & $\mathrm{M}, \mathrm{Q}, \mathrm{F}, \mathrm{Mi}$ & $\mathrm{Mn}, \mathrm{M} / \mathrm{TM}, \mathrm{H}, \mathrm{Q}, \mathrm{Al}$ \\
\hline & PP9-466 & PP9-III & TM, Q, F & $\mathrm{Mn}, \mathrm{M} / \mathrm{TM}$ \\
\hline Negro sobre naranja & $55 \mathrm{v}$ & PC3c & $\mathrm{M}, \mathrm{H}, \mathrm{Q}, \mathrm{Mi}$ & $\mathrm{Mn}, \mathrm{M} / \mathrm{TM}, \mathrm{H}, \mathrm{PO}_{4}$ ?, Q \\
\hline \multirow{3}{*}{ Engobe pulido } & PQ66A & PQ1 & Sin analizar & $\mathrm{M}, \mathrm{H}, \mathrm{An}, \mathrm{Q}, \mathrm{Mu}$ \\
\hline & PQ33 & PQ2 & $\mathrm{M}, \mathrm{H}, \mathrm{Q}, \mathrm{F}$ & $\mathrm{M}, \mathrm{H}, \mathrm{An}, \mathrm{Q}$ \\
\hline & PQ66B & PQ1 & M, Q, F, MI & Sin analizar \\
\hline
\end{tabular}

Las muestras del grupo «engobe pulido» conforman un caso particular: algunos fragmentos poseen un color negro o gris oscuro homogéneo en ambas superficies, en cambio en otros la superficie externa posee tonalidades rojas y negras con límites difusos (Fig. 2B). El color rojo se identificó como hematita (Fig. 16) y el negro como magnetita (Fig. 15a). La presencia de esta última puede atribuirse a la reducción de parte de la hematita por efecto de la presencia de gases reductores $(\mathrm{CO})$ y la baja presión parcial de oxígeno en la atmósfera del horno durante la cocción, así como también, por el eventual contacto directo de las piezas con el combustible orgánico parcialmente quemado (Puente et al. 2019).

Además, cabe mencionar que en todos los casos se identificó cuarzo y feldespatos y, en algunas muestras, independientemente del sitio de hallazgo y estilo, se reconoció la presencia de hematita, anatasa, mica y fosfatos (Tabla 4). Respecto a los fosfatos, por el momento no podemos distinguir si su presencia se debe a alteraciones posdepositacionales o si formaron parte de las pinturas. En cambio, el resto posiblemente formó parte de las mezclas pigmentarias naturales y/o se integraron en la preparación de las pinturas, por ejemplo, con la incorporación de los ligantes.

\section{Discusión y conclusiones}

La identificación de los componentes minerales que conforman las pinturas y engobes de la cerámica de ambas quebradas permitió avanzar en el conocimiento de las elecciones realizadas por los alfareros en parte del proceso de elaboración de los recipientes. Los minerales identificados como responsables de las pinturas de color rojo y negro coinciden en las muestras estudiadas, más allá de las diferencias estilísticas, tecnológicas y del sitio de hallazgo: hematita para los rojos y, una combinación de óxidos de manganeso y magnetita y/o titanomagnetita para los negros. 


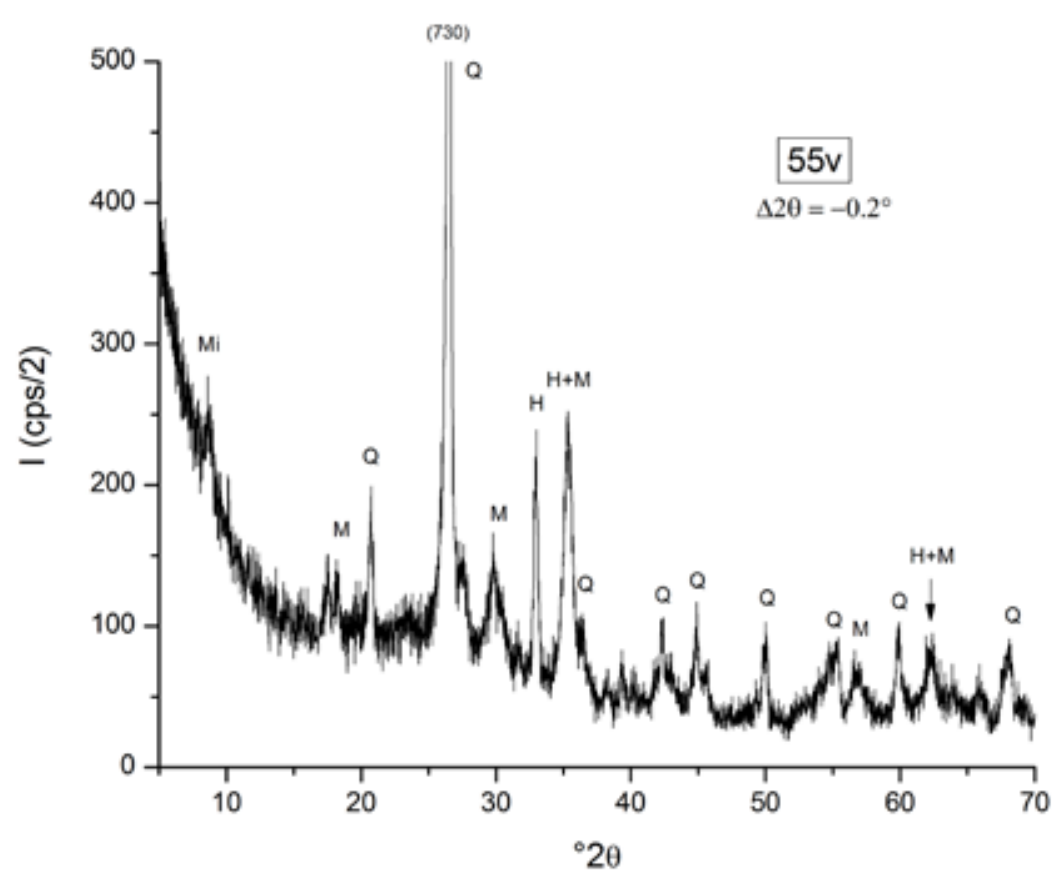

Figura 14. Ejemplo de difractograma de pintura negra, muestra cerámica $55 v$ (negro sobre naranja). Referencias: $Q$ (cuarzo), Mi (micas), H (hematita), M (magnetita) (J. M. Porto López).

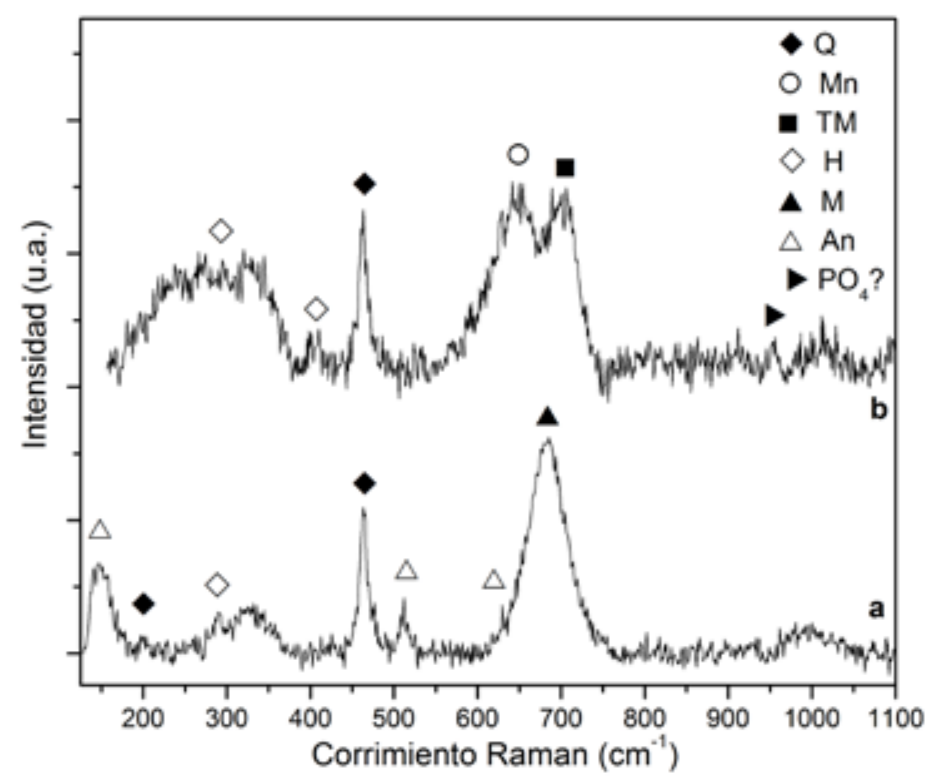

Figura 15. Espectros Raman comparativos: a) engobe negro de una muestra "engobe pulido" de Paicuqui (PQ33); b) pintura de color negro de una cerámica de Las Pitas (55v). Referencias: Q (cuarzo), Mn (óxidos de manganeso), TM (titanomagnetita), $\mathrm{H}$ (hematita), $\mathrm{M}$ (magnetita), An (anatasa), $\mathrm{PO}_{4}$ (fosfatos) (P. M. Desimone). 


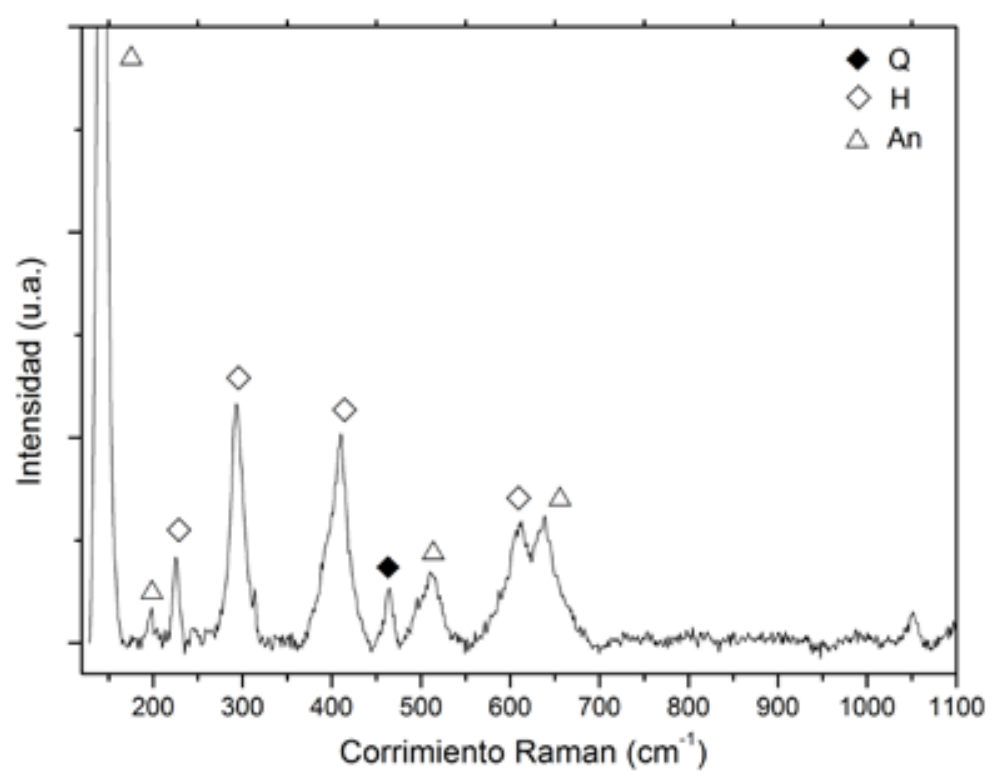

Figura 16. Espectro Raman correspondiente al color rojo de la muestra PQ33. Referencias: $Q$ (cuarzo), $H$ (hematita), An (anatasa) (P. M. Desimone).

La homogeneidad composicional en los precursores minerales empleados para lograr la pintura negra es destacable, sobre todo teniendo en cuenta que los antecedentes disponibles en distintos sitios del NOA muestran variabilidad de compuestos (De la Fuente y Pérez Martínez 2008; Acevedo et al. 2012; Bugliani et al. 2012; Puente et al. 2017). Del mismo modo que las piezas y los saberes de manufactura han circulado entre sitios y regiones, los pigmentos fueron objeto de intercambio, solo que los datos que se han generado sobre ellos son aún escasos. Así, los minerales negros utilizados para las pinturas de las piezas elaboradas en la región pueden proceder de las mismas fuentes que los usados en recipientes pintados que circularon desde otras zonas, como es el caso de la muestra PC2 10-15 de estilo Belén. El avance en los estudios arqueométricos del color, sobre pigmentos y pinturas permitirá poner a prueba esta hipótesis. También es necesario evaluar la utilización de alguna técnica analítica que permita comparar elementos traza de los minerales coloreados.

A diferencia de ello, en la cerámica hallada en Paicuqui, sobre la cual se aplicó una gruesa capa de engobe, los óxidos de manganeso están ausentes. Consideramos que el engobe fue originalmente de color rojo - hematita — , y el color negro — magnetita — se obtuvo debido al proceso y las condiciones de cocción (Puente et al. 2019).

En relación con las fuentes de pigmentos que afloran en Paicuqui —único lugar detectado hasta el momento en ANS_- la diferencia entre las tonalidades de los minerales rojos respecto a los blancos y grises, se establece principalmente, por la presencia de hierro férrico (hematita y goethita) en los primeros y su ausencia en los segundos. La anatasa se identifica en algunos depósitos de color gris claro y aparece junto con clorita o kaolinita. Esta última, al igual que la hematita están presentes en la mayoría de los depósitos analizados, independientemente de su color.

De estos minerales locales, solo la hematita se identificó en las pinturas y engobes de las cerámicas analizadas. El uso de la goethita no puede evaluarse en muestras que pasaron por un proceso de cocción como el de la cerámica, ya que este mineral se transforma a maghemita y/o hematita a partir de $300{ }^{\circ} \mathrm{C}$ (Balek y Subrt 1995). Igualmente, los datos que tenemos hasta el momento no nos permiten asegurar ni descartar que se hayan utilizado esos depósitos para colorear la cerámica. Con respecto a los pigmentos blancos y grises que afloran en la región, no hemos detectado aún su 
uso para la manufactura de alfarería local, ya que esta, cuando es pintada, es de color rojo y negro. Sin embargo, en distintos sitios a lo largo del río Punilla se recuperaron fragmentos de cerámica de estilo Santamariano negro sobre crema (Vigliani 1999; Pérez y Gasparotti 2016; Puente et al. 2018), posiblemente procedentes del valle de Yocavil o de sitios de los valles Calchaquíes, lugares donde abunda ese estilo cerámico. La kaolinita se detectó en el color crema de este tipo de piezas en muestras del valle de Yocavil y en el valle vecino de El Bolsón, pero no se han hallado los depósitos de dichas materias primas en esas regiones (Palamarczuk 2002; Puente, Desimone y Porto López 2017). Entonces, cabe preguntarse si esos minerales circularon desde ANS, dadas las relaciones de interacción registradas desde otras líneas de evidencia (Pérez y Gasparotti 2016; Martel 2014; Puente, Plá e Invernizzi 2017). Los datos alcanzados hasta el momento no permiten responder este interrogante, pero generan un antecedente a considerar y un tema a profundizar en futuros trabajos.

Por otra parte, los microrrestos conservados en la mano del mortero muestran que fue utilizada para moler distintas sustancias colorantes; entre ellas la hematita y la anatasa se registran en Paicuqui, en tanto el yeso y la magnetita no han sido identificados por el momento. Respecto a este último mineral, cabe destacar que, si bien aún no se encontraron depósitos, entre la peña 1 y 2 de Paicuqui, el dispositivo utilizado para volar un dron (DJI Phantom 3 Standard) detectó una zona de alto magnetismo, por lo tanto, no podemos descartar que este componente esté presente. Por ello, destacamos la necesidad de realizar nuevas prospecciones y muestreos.

La composición del «pan de pigmentos» — hematita, goethita, arcilla del grupo de las micas, kaolinita y cuarzo - es coherente con las materias primas que afloran en Paicuqui, razón por la cual consideramos que se elaboró con los materiales de la zona. Si bien en Paicuqui no se detectó hasta el momento cerámica de origen local (Puente et al. 2018), los pigmentos del sitio fueron utilizados, tal vez para pintar cerámicas de otros sectores de la microrregión donde hubo producción alfarera, como por ejemplo en sitios de las quebradas de Las Pitas, Miriguaca y fondo de cuenca del Punilla, y también sobre otros soportes. Respecto a esto último, cabe destacar que en ANS se reconoció el uso de hematita junto a otros compuestos en pinturas rupestres en el sitio Cacao 1 y hematita y goethita en las pinturas de los sitios Quebrada Seca 1 y 2 (Aschero y Podestá 1986; Lépori et al. 2018). Asimismo, en sustancias coloreadas recuperadas en estratigrafía en sitios de Punta de la Peńa se identificó el uso de hematita y kaolinita entre otros compuestos (Babot y Apella 2012). El hierro también se utilizó para colorear fibras vegetales y animales encontradas en sitios de la región (López Campeny et al. 2018).

Finalmente, se destaca la importancia de generar una base de datos sobre los minerales colorantes que afloran en la zona, dado que constituye una referencia para los estudios de pigmentos sobre distintos soportes. Además, considerando que estas materias primas fueron objeto de intercambio, conocer la ubicación de los afloramientos y su composición — muchas veces ausentes en las cartas geológicas debido a su escala— son datos fundamentales para avanzar en el conocimiento de las redes y prácticas de interacción que actuaron en el pasado, además de contribuir al entendimiento de las prácticas locales.

\section{Agradecimientos}

Nuestro agradecimiento a la doctora Isabelle Druc por invitarnos a participar del Simposio Internacional Avances en el Análisis de Cerámicas y Pigmentos, que tuvo lugar en Lima, en la Pontificia Universidad Católica de Perú. Este trabajo fue financiado con dos subsidios de la Agencia Nacional de Promoción Científica y Tecnológica de Argentina (PICT 2067 y PICT 2595). 


\section{REFERENCIAS}

Acevedo, V., M. A. López, E. Freire, E. B. Halac, G. Polla y M. Reinoso

2012 Estudio de pigmentos en alfarería estilo Negro sobre Rojo de Quebrada de Humahuaca, Jujuy, Argentina, Boletin Chileno de Arte Precolombino 17 (2),39-51.https://doi.org/10.4067/S0718-68942012000200004

Akyuz, S. T. Akyuz, S. Basaran, C. Bolcal y A. Gulec

2008 Analysis of ancient potteries using FT-IR, micro-Raman and EDXRF spectrometry, Vibrational Spectroscopy 48, 276-280. https://doi.org/10.1016/j.vibspec.2008.02.011

Aschero, C.

1988 De punta a punta: producción, mantenimiento y diseño de puntas de proyectil precerámicas de la Puna Argentina, en: Precirculados de las ponencias cientificas a los simposios del IX Congreso Nacional de Arqueología Argentina (1988), 219-229, Facultad de Filosofía y Letras, Universidad de Buenos Aires, Buenos Aires.

Aschero, C. y M. Podestá

1986 El arte rupestre en asentamientos precerámicos de la Puna Argentina, Runa 26, 29-57.

Babot, M. P y M. C Apella

2012 Colores y pigmentos en contexto, en: Resúmenes del VIII Simposio Internacional de Arte Rupestre (2010), 15-19, Instituto de Arqueología y Museo, Instituto Superior de Estudios Sociales, Secretaría de Ciencia y Técnica de la Universidad Nacional de Tucumán, San Miguel de Tucumán.

Balek, V. y J. Subrt

1995 Thermal behaviour of iron oxide-hydroxides, Pure \& Applied Chemistry 67 (11), 1839-1842. https://doi. org/10.1351/pac199567111839

Bugliani, M. F., C. Di Lello, E. Freire, G. Polla, A. Petragalli, M. Reinoso y E. Halac

2012 Empleo de Espectroscopía Raman, Difracción de rayos X y Microscopía electrónica para el análisis de Pigmentos en Cerámicas Vaquerías, Boletín Chileno de Arte Precolombino 17 (2), 65-74. https://doi. org/10.4067/S0718-68942012000200006

Cohen, M. L.

2005 Entre guano y arena. Ocupaciones recurrentes: un caso de estudio en el sitio Punta de la Peña 9-III, Antofagasta de la Sierra, Catamarca, tesis de grado en Arqueología, Facultad de Ciencias Naturales e Instituto Miguel Lillo, Universidad Nacional de Tucumán, San Miguel de Tucumán.

2014 Miradas desde y hacia los lugares de poder. Antofagasta de la Sierra entre el 1000 y 1500 D.C., Arqueología $20(1), 47-72$.

Cohen, M. L. y A. Ponce

2016 Paisajes ensamblados: Cielo y tierra en Paicuqui, Antofagasta de la Sierra, Catamarca, en: Actas del XIX Congreso Nacional de Arqueología Argentina (2016), Serie Monográfica y Didáctica 54, 2461-2467, Facultad de Ciencias Naturales e Instituto Miguel Lillo, Universidad Nacional de Tucumán, San Miguel de Tucumán.

De la Fuente, G. y J. M. Pérez Martínez

2008 Estudiando pinturas en cerámicas arqueológicas «Aguada Portezuelo» (ca. 600-900 AD) del noroeste argentino: nuevos aportes a través de una aproximación arqueométrica por microespectroscopía de Raman (MRS), Intersecciones en Antropología 9, 173-186.

Escola, P., A. Elías y M. L. Cohen

2016 Obsidianas en el Tardío- Inka de Antofagasta de la Sierra (Puna meridional argentina): ¿fondo de cuenca versus sectores intermedios?, Arqueología 22 (1), 211-222.

Hong, F. y R. Seggiano

2001 Programa nacional de cartas geológicas de la República Argentina. Hoja Geológica 2566-III Cachi, Instituto de Geología y Recursos Minerales, Servicio Geológico Minero Argentino, Buenos Aires. 
Kloprogge, J. T.

2017 Infrared and Raman Spectroscopies of Clay Minerals, en: W. P. Gates, J.T. Kloprogge, J. Madejová, F. Bergaya (eds.), Developments in clay science vol. 8, 1-604, Elsevier, Amsterdam. https://doi.org/10.1016/ B978-0-08-100355-8.00012-6

Lépori, M., M. Sepúlveda, C. Aschero, S. Gutiérrez y J. Cárcamo

2018 Los colores de la modalidad estilística Confluencia y Derrumbes (ca. 1000-550 AP) en el sitio Cacao 1A (Antofagasta de la Sierra, Catamarca, Argentina). Arqueometría y caracterización físico-química de pigmentos rupestres, ponencia presentada al XI Simposio Internacional de Arte Rupestre, La Serena, Chile.

López Campeny, S. M. L., A. Romano, M. F. Rodríguez, A. Martel y M. Corbalán

2014 De aquí y de allá: análisis integral de un contexto funerario. Vínculos e interacciones sociales entre Puna meridional y Tierras Bajas orientales, Intersecciones en Antropología 15, 201-218.

López Campeny, S. M. L., S. Suárez, B. Quiroga, A. S. Romano, M. P. Babot, S. Hocsman, J. G. Martínez y M. S. Martínez

2018 Uso del color en textiles: Antofagasta de la Sierra, Catamarca (ca. 8000 a 200 años AP). Caracterización por PIXE, en: Libro de resúmenes extendidos, VII Congreso Nacional de Arqueometría (2018), Serie Monográfica y Didáctica 56, 226-231, Facultad de Ciencias Naturales e Instituto Miguel Lillo, Universidad Nacional de Tucumán, San Miguel de Tucumán.

Martel, A.

2014 Aguas Calientes. Evidencias directas de tráfico caravanero entre la Puna meridional y el valle Calchaquí, Estudios Sociales del NOA 13, 103-124.

Martel, A., D. Zamora y M. Lépori

2017 Tráfico y movilidad caravanera en la puna catamarqueña. Una mirada intermodal, Estudios Atacameños 56, 197-223. https://doi.org/10.4067/S0718-10432017005000004

Murad, E.

1997 Identification of minor amounts of anatase in kaolins by Raman spectroscopy, American Mineralogist 82, 203-206. https://doi.org/10.2138/am-1997-1-222

Palamarczuk, V.

2002 Análisis cerámicos de sitios del bajo de Rincón Chico Valle de Yocavil, Provincia de Catamarca, tesis de Licenciatura en Ciencias Antropológicas, orientación Arqueología, Facultad de Filosofía y Letras, Universidad de Buenos Aires, Buenos Aires.

Pérez, M. y L. Gaspatotti

2016 Caracterización petrográfica de las pastas cerámicas de Antofagasta de la Sierra (Puna Austral Argentina). Un enfoque comparativo a nivel intersitios, Comechingonia. Revista de Arqueología 20 (1), 175-202.

Ponce, A. y M. L. Cohen

2018 Esperando a que salga el sol. Arquitectura y percepción en Paicuqui, Antofagasta de la Sierra (Catamarca), en: Libro de Resúmenes Extendidos, Congreso Nacional de Arqueometría (2018), 263-268, Facultad de Ciencias Naturales e Instituto Miguel Lillo, Universidad Nacional de Tucumán, San Miguel de Tucumán.

Puente, V.

2016 Delineando prácticas de producción y consumo de alfarería en Antofagasta de la Sierra: la cerámica de Peñas Coloradas 3 ca. 1000-1600 DC (Catamarca, Argentina), Revista Española de Antropología Americana 46, 241-263. https://doi.org/10.5209/REAA.58296

Puente, V., P. M. Desimone y J. M. Porto López

2017 Nuevos aportes sobre la composición de las pinturas de la cerámica santamariana procedente del valle de El Bolsón (Belén, Catamarca), ponencia presentada en modalidad poster a las en las $3^{\text {ras }}$ Jornadas Nacionales en Investigación Cerámica (INTEMA-CONICET), Universidad Nacional de Mar del Plata, Mar del Plata.

2018 Vasijas y materias primas locales: aproximación arqueométrica al estudio de la alfarería de Paicuqui (Antofagasta de la Sierra, Argentina), en: Libro de Resúmenes Extendidos, Congreso Nacional de Arqueometría (2018), 119-222, Facultad de Ciencias Naturales e Instituto Miguel Lillo, Universidad Nacional de Tucumán, San Miguel de Tucumán. 
Puente V., P. M. Desimone, J. P. Tomba y J. M. Porto López

2017 Compositional variability of pigments of Belén-style prehispanic ceramics from El Bolsón Valley, Catamarca Province, Argentina, Journal of Archaeological Science: Reports 12 (2017) 553-560. https://doi. org/10.1016/j.jasrep.2017.03.007

Puente, V., R. Plá y R. Invernizzi

2017 La cerámica local de la quebrada del río Las Pitas (Catamarca). Aportes a la circulación de personas, saberes y objetos en Antofagasta de la Sierra durante el tardío, Relaciones de la Sociedad Argentina de Antropologia XLII (1/2), 35-61.

Puente, V., J. M. Porto López, P. M. Desimone y P. M. Botta

2019 The persistence of the black color in magnetite-based pigments in prehispanic ceramics of the Argentine Northwest, Archaeometry 61(5), 1066-1080. https://doi.org/10.1111/arcm.12476

Quiroga, L.

2014 Paisajes de rebeldía: Reproducción, identidades y resistencia en la serranía de Londres (Gobernación del Tucumán) Siglos XVI Y XVII, Revista de Arqueología Americana 32, 151-175.

Somonte, C. y M. L. Cohen

2006 Reocupación y producción lítica: un aporte a la historia ocupacional de los recintos 3 y 4 del sitio agropastoril de Punta de la Peña 9-Sector III (Antofagasta de la Sierra, Catamarca, Argentina), Werkén 9, $135-158$.

Vigliani, $S$.

1999 Cerámica y asentamiento: sistema de producción agrícola Belén-Inka, tesis de licenciatura, Facultad de Filosofía y Letras, Universidad de Buenos Aires, Buenos Aires.

Recibido: 31/01/2019

Aceptado: $31 / 07 / 2019$ 